\title{
Skin metastases revealing lung cancer
}

\author{
Selma Benkirane*, Mounia Bennani, Sara Elloudi, Hanane BayBay, and Fatima Zahra Mernissi \\ Department of Dermatology, University Hospital Hassan II, Fez, Morocco
}

Corresponding Author: Selma Benkirane, Department of Dermatology, University Hospital Hassan II, Fez, Morocco

Received date: May 27 2020; Accepted date: June 22, 2020; Published date: June 25, 2020

Citation: Selma Benkirane, Mounia Bennani, Sara Elloudi, Hanane BayBay and Fatima Zahra Mernissi; Clinical Medical Reviews and Reports, 2(4); DOI: 10.315792690-8794//024

Copyright: () 2020, Selma Benkirane. This is an open access article distributed under the Creative Commons Attribution License, which permits unrestricted use, distribution, and reproduction in any medium, provided the original work is properly cited.

\section{Introduction:}

Skin metastases represent an infrequent secondary location of deep cancers. They represent 0.6 to $10 \%$ of metastases from solid tumors [1]. We are reporting a case

\section{Observation:}

60-year-old patient, chronic smoking for 30 years not weaned, consulted in dermatology for painless lesions in the trunk gradually increasing in size. On clinical examination, these were two cutaneous nodules of the angiomatous type, measuring for the largest $3 \mathrm{~cm}$ in diameter with a firm and painless character sitting at the high level of the trunk [Figure 1] without tendency to spontaneous regression of lesions. Dermoscopic examination revealed a milky red area, tortuous vessels, and a rainbow appearance [Figure 2].The whole evolving in a context of apyrexia and deterioration of the general state. The rest of the examination was normal, especially the lymph nodes. The patient underwent a biopsy with a histological result in favor of a secondary location. A thoracic CT scan was performed showing a right para-hilar tissue process with confirmation of a bronchial adenocarcinoma by fibroscopy. The extension assessment, notably a bone scan and a cerebral, abdominal and pelvic computed tomography complement, was without particularities. The patient was referred to oncology for possible polychemotherapy and additional management.

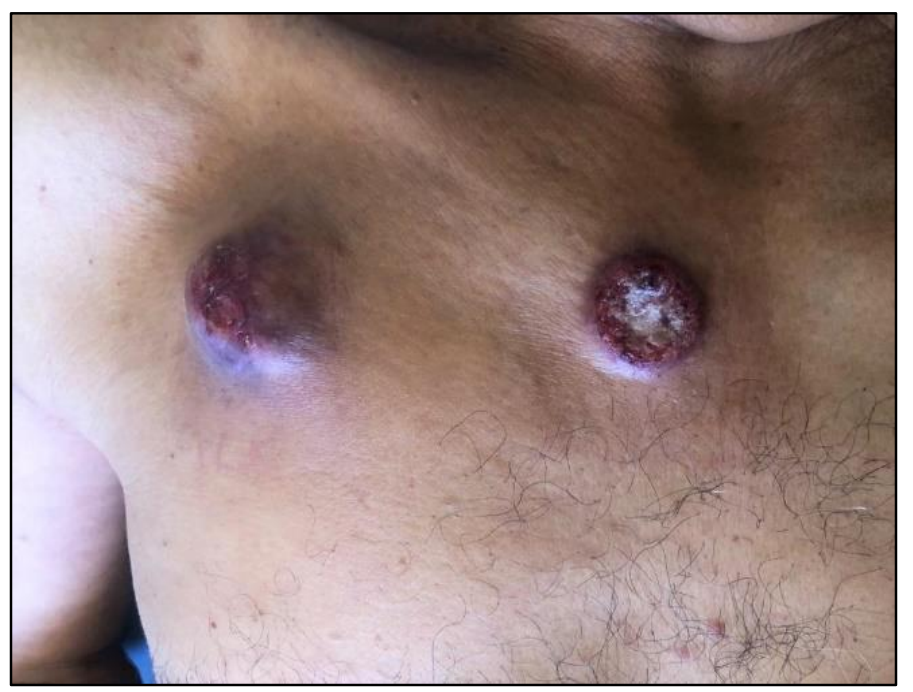

Figure 1: Presence of two angiomatous skin nodules, measuring for the largest $3 \mathrm{~cm}$ in diameter at the trunk.

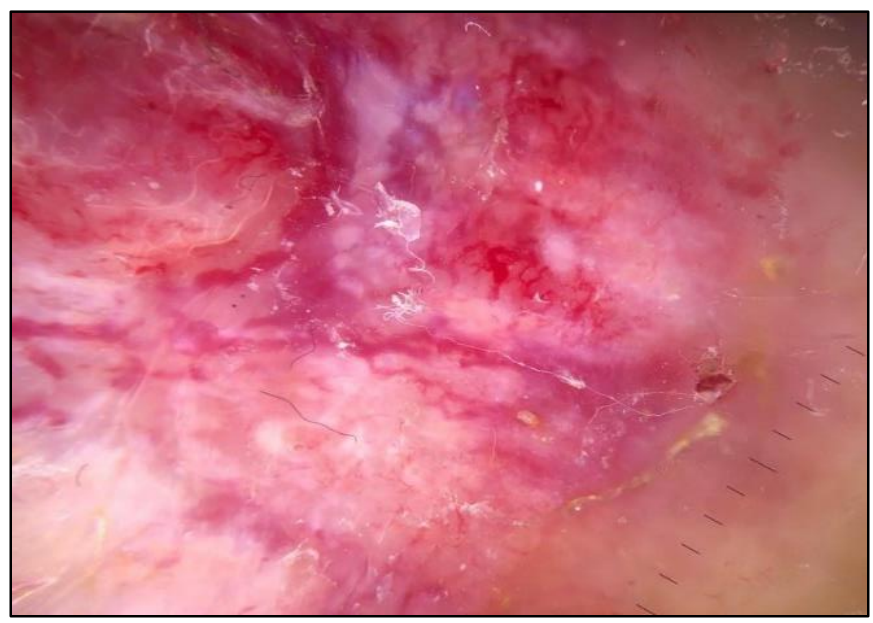

Figure 2: Dermoscopic examination revealed a milky red area, tortuous vessels, and a rainbow appearance

\section{Discussion:}

Cutaneous metastases represent about $2 \%$ of all skin tumors [2] and are usually associated with a poor prognosis, being a hallmark of widely spread visceral disease. Moreover, they can be the first sign of an asymptomatic, yet occult malignancy [3]. Several series have found that melanoma is the most frequent primary neoplasm leading to cutaneous metastases [4]. After melanoma, lung cancer is the most frequent origin of cutaneous metastases in men and breast cancer in women [5]. Lung cancer is often diagnosed at a metastatic stage, with a predilection for lymph node, pleural, contralateral pulmonary, cerebral, bone and adrenal localizations. Skin metastases are rare with an incidence of $2.9-5.3 \%$ for all cancers and $1-12 \%$ for lung cancer. The lesions are often made of a single nodule with several immobile hard subcutaneous with a size varying from $(0.5$ to $10 \mathrm{~cm})$, the skin metastases of pulmonary origin are often of the adenocarcinoma type followed by the epidermal carcinoma as well as the carcinoma pulmonary with small cells, our patient presented two subcutaneous nodules of which one ulcerated.

Conflicts of interest: "The authors have declared that they have no conflict of interest."

\section{Conclusion:}

Careful clinical examination, the site of the lesions and the sex of the patient point to skin metastases due to solid cancer. However, histological and immunohistochemical examination remains the key to the diagnosis. 


\section{References:}

1- Alcaraz, I., Cerroni, L., Rütten, A., Kutzner, H., \& Requena, L. (2012).Cutaneous Metastases from Internal Malignancies. The American Journal of Dermatopathology, 34(4), 347-393.

2- Nashan D, Meiss F, Braun -Falco M, Reichenberger S.(2010) Cutaneous metastases from internal malignancies. Dermatologic Therapy; 23(6):567 -80.

3- Hu S, Chen G, Lu Y, Wu C, Lan C.(2008)Cutaneous metastases from different internal malignancies: a clinical and prognostic appraisal. Journal of the European Academy of Dermatology and Venereology; 22(6):735 40.

4- Lookingbill DP, Spangler N, Helm KF. (1993) cutaneous metastases in patients with metastatic carcinoma: A retrospective study of 4020 patients. Journal of the American Academy of Dermatology; 29(2):228 -36.

5- Fernandez -Flores A. (2010) Cutaneous Metastases: A Study of 78 Biopsies from 69 patients. The American Journal of Dermatopathology;32(3):222 -39 